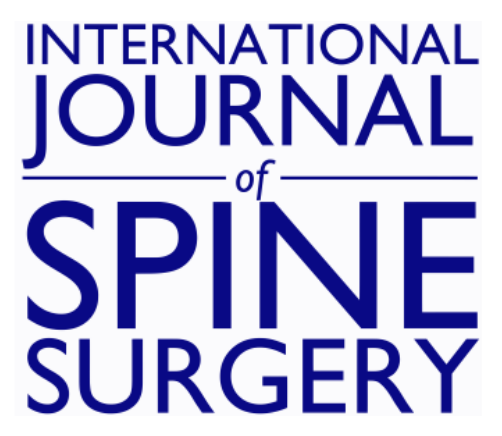

\title{
Single-Stage Combined Anterior Corpectomy and Posterior Instrumented Fusion in Tuberculous Spondylitis With Varying Degrees of Neurological Deficit
}

Ujjwal K. Debnath, Jeffrey R. McConnell and Sishir Kumar

Int J Spine Surg 2021, 15 (3) 600-611

doi: https://doi.org/10.14444/8081

http://ijssurgery.com/content/15/3/600

This information is current as of April 26, 2023.

Email Alerts Receive free email-alerts when new articles cite this article. Sign up at:

http://ijssurgery.com/alerts

The International Journal of Spine Surgery

2397 Waterbury Circle, Suite 1,

Aurora, IL 60504, Phone: +1-630-375-1432 


\title{
Single-Stage Combined Anterior Corpectomy and Posterior Instrumented Fusion in Tuberculous Spondylitis With Varying Degrees of Neurological Deficit
}

\author{
UJJWAL K. DEBNATH, MS(Orth), FRCSG, FRCS(Tr \& Orth), DM(Orth) University of Nottingham, CCT-UK, ${ }^{1}$ \\ JEFFREY R. MCCONNELL, MD, ${ }^{2}$ SISHIR KUMAR, MS(Gen Surg), Dip Ortho, MCh(Ortho) ${ }^{3}$ \\ ${ }^{1}$ Ramakrishna Mission Seva Pratisthan, Kolkata, India, ${ }^{2}$ Leigh High Valley Hospital, Allentown, Pennsylvania, ${ }^{3}$ Metro Hospital, New Delhi, India
}

\begin{abstract}
Background: A combined anterior decompression and stabilization followed by posterior instrumented fusion promotes fusion of the affected segment of spine and prevents further progression of deformity. The objective of this study is to report on outcome of patients with tuberculous spondylitis, progressive neurologic deficit, and kyphotic deformity who underwent single-stage anterior corpectomy and fusion and posterior decompression with instrumented fusion.

Methods: A total of 49 patients (29 males, 20 females) with varying grades of neurological deficit due to tuberculosis of the spine (thoracic, thoracolumbar, and lumbar) were included in this prospective study. The diagnosis of tubercular infection was established after clinical, hematological, radiological, and histological specimens taken at surgery. All were treated with combined anterior and posterior decompression, debridement, and stabilization with direct autologous bone grafting or wrapped bone graft in mesh or expandable cages. Neurological status and visual analog scale (VAS) pain score were recorded at each visit. X-rays, erythrocyte sedimentation rate (ESR), C-reactive protein (CRP), and liver function were evaluated at 3, 6, and 12 months after surgery and then once a year thereafter. Results were analyzed in terms of neurological recovery (Frankel grade), bony union time, and correction of kyphotic deformity.

Results: The mean age was 37.8 years (range, 2-65 years). Mean preoperative VAS scores improved from 5.6 to 1.5. The average ESR and CRP returned to normal within 6 months in all patients. The mean time to fusion was 8.4 months for the whole group. The neurological deficit in 42 of 49 patients had excellent or good clinical outcome $(P<$ $.0001)$. A total of 10 of 17 patients improved from Frankel A and B to Frankel E (normal activity). Three patients each in the thoracic and thoracolumbar groups improved to Frankel D. Radiological measurements showed the mean kyphotic correction was $61 \%, 66 \%$, and $67 \%$ in the thoracic, thoracolumbar, and lumbar/lumbosacral spine, respectively.

Conclusions: Combined single-stage anterior decompression and stabilization followed by posterior instrumented fusion is safe and effective in the treatment of tuberculous spondylitis with neurological deficit in the thoracic and lumbar spine. This procedure helps to correct and maintain the deformity, abscess clearance, spinal-cord decompression, and pain relief as well as return to normal motor function. Bony fusion prevents further progression of deformity.
\end{abstract}

Level of Evidence: 2.

Other \& Special Categories

Keywords: spine tuberculosis, neurological deficit, combined anterior and posterior surgery (A-P), spinal fusion

\section{INTRODUCTION}

The first modern description of spinal deformity and paraplegia resulting from spinal tuberculosis (TB) was described by Percival Pott in $1779 .{ }^{1,2}$ The treatise showed the relation between caries of the vertebrae and paralysis of the extremities. ${ }^{3}$ The diagnosis of spinal TB is difficult, and it commonly presents at an advanced stage. The neural deficit in Pott disease is relatively benign if urgent decom- pression is performed. ${ }^{4}$ The thoracolumbar junction seems to be the most common site of involvement. ${ }^{5}$ Recently, the development of multidrug-resistant TB (MDR-TB), advanced imaging modalities, and modern spinal reconstruction techniques have changed the management of Pott disease. ${ }^{5}$ Indications for surgical management of patients are spinal instability, progression of neurological deficit, and being refractory to conservative treatment. Various 
surgical strategies are available including surgical debridement of infected material from the site followed by anterior spinal fusion alone, combined anterior-posterior (A-P) spinal fusion, posterior spinal fusion alone, and posterior fusion followed by anterior spinal fusion. ${ }^{6-9}$ However, the indication for each surgical procedure remains unclear, given the lack of literature on the safety, neurological outcomes, and complication rates. ${ }^{10}$

The objective of this study was to report on outcome of patients with tuberculous spondylitis, progressive neurologic deficit, and kyphotic deformity who underwent single-stage anterior corpectomy and fusion and posterior decompression with instrumented fusion.

\section{MATERIAL AND METHODS}

A total of 50 patients (30 males, 20 females) with varying degrees of sensory motor deficit following spinal TB were prospectively evaluated at 2 centers. Multicenter study ethics approval was granted by the local institutional ethics board. Informed consent was obtained from all. The diagnosis of TB spondylitis was established following clinical manifestations supported by radiological and hematological examination, supplemented by postoperative histopathological examination. Active TB was diagnosed on the basis of clinical symptoms (weight loss, low-grade fever, night sweats, and fatigue); laboratory findings (high erythrocyte sedimentation rate [ESR] and C-reactive protein [CRP]); and chest radiograph. One patient was lost to follow-up after 4 months and therefore was excluded from the study. Thus, we had 49 patients (29 males, 20 females) in the final study group.

The spinal regions involved were thoracic (19), thoracolumbar (18), and lumbar or lumbosacral (12). The X-rays were evaluated for the number of vertebral involvements, posterior lesions, and kyphosis angles. The kyphosis angle was measured according to the method of the British Medical Research Council. ${ }^{11}$ Loss of vertebral body was assessed as described. ${ }^{12}$ The most cephalad and caudal vertebral bodies involved were T4 and S1, respectively. Computed tomography (CT) or MRI scans were evaluated for level of lesion, amount of vertebral destruction, soft tissue extension, presence of epidural pus, spinal cord compression, and signal changes. Preoperative CT or MRI revealed canal and paraspinal abscesses in all patients but 2 .
The disease in 17 patients was characterized by Frankel grade A/B (Medical Research Council Grade 0/5) and in 24 patients by Frankel grade C (unable to walk even with support); 8 patients had Frankel grade D (walk with support but weak legs) on admission, 4 of whom deteriorated to Frankel C. Nine of $49(20 \%)$ patients had an associated primary lung focus (some had healed on chest radiographs) or had reported history of pulmonary TB. None had clinical respiratory symptoms.

Antituberculosis therapy (ATT) was initiated in all patients and continued for 4 weeks before surgery. All patients were required to have ESRs at $<40 \mathrm{~mm} / \mathrm{h}$ and hemoglobin of $>10 \mathrm{~g} / \mathrm{dL}$ before surgery. This protocol has been followed by many previous authors. ${ }^{13-21}$ Emergency surgery was performed for patients with a sudden onset of complete paralysis. Indications for surgery were therapeutically refractory disease, panvertebral lesions, an expanding cold abscess, severe kyphosis, and neurological deficit. ${ }^{22}$

All the patients underwent single-stage anterior corpectomy, debridement with cage or rib/iliac crest bone graft insertion, and posterior instrumented fusion. Physiotherapy was instituted in all patients. All had a minimum of 24 months of follow-up (mean follow-up period was 32 months) with a range of $18-60$ months.

\section{SURGICAL PROCEDURE}

\section{Thoracic Spine}

Under general anesthesia, surgery was performed with the patient in the lateral decubitus. After exposure through an anterolateral approach depending on the level of the lesion and the necrotic tissue in the disc, a corpectomy was performed. After thorough debridement, distraction was performed to correct kyphosis. Exposing the thoracolumbar junction required a long, curvilinear incision from the lateral thorax to the medial abdomen. The surgical exposure used was described by Hodgson and Stock $^{23}$ (ie, removing the 11 th rib, entering the retroperitoneum, and retracting structures forward to expose the lower thoracic and upper lumbar spine). The diaphragm may be incised longitudinally at the spine or at its periphery. For greater exposure, the costochondral cartilage was divided.

Corpectomy, followed by either autogenous strut or cancellous bone grafting wrapped in a cage (either mesh or expandable), was performed to 
reconstruct the anterior column defect. Once kyphotic correction and segmental stability was achieved, the patient underwent a posterior instrumented fusion in a prone position.

\section{Lumbar Spine}

The patient was usually positioned in lateral decubitus. Usually a left paramedian incision for exposing L4-L5 and a right paramedian exposure for L5-S1 centered on this skin marking midway between the umbilicus and symphysis pubis was used. A self-retaining retractor, the Syn-Frame (Synthes-Retractor System; Synthes, Paoli, PA), aided in exposure of the lumbar spine. An adequate exposure of the region was followed by ligation of segmental vessels. Following initial drainage, the abscess was opened and irrigated thoroughly with warm saline. The tuberculous collapsed vertebrae and intervertebral discs were thoroughly debrided until healthy bleeding margins were obtained. After sufficient spinal cord decompression, suitable strut grafts, mesh cage, or expandable cages were used to achieve deformity correction and segmental stability. The incision was sutured after confirmation with C-arm fluoroscopy.

\section{Postoperative Regime}

A TLSO (thoracolumbosacral orthosis) brace for thoracolumbar support was provided to each patient, which was continued for at least 3 months until the patient had reduced pain. The ATT was administered for at least 18 months postoperatively. Chemotherapy was tailored for those patients in whom drug sensitivity test results indicated resistance to any first-line drug. If MDR-TB was detected, levofloxacin was added along with an injectable.

\section{Follow-Up Evaluation}

Neurological status and visual analog scale (VAS) pain score was recorded at each visit. Xrays, erythrocyte sedimentation rate (ESR), Creactive protein (CRP), and liver function were evaluated at 3, 6, and 12 months after surgery and then once a year thereafter. Patients who met the following criteria were considered healed of disease: (1) clinical improvement, (2) return of ESR and CRP to normal levels, (3) radiographs showing signs of fusion, and (4) no recurrence of $\mathrm{TB}$ at the end of 2 years.
Table 1. Clinical data of patients.

\begin{tabular}{lc}
\hline Parameter & Value \\
\hline Gender & \\
$\quad$ Male & 29 \\
Female & 20 \\
Age, average (range), y & $37.8(2-65)$ \\
Affected levels & 19 \\
$\quad$ Thoracic & 18 \\
Thoracolumbar & 12 \\
Lumbar/lumbosacral & 1.7 \\
Mean number of vertebrae involved & \\
\hline
\end{tabular}

\section{Statistical Analysis}

For data analysis, SPSS for Windows (version 20.0; IBM Corp, Armonk, NY) was used. A paired $t$ test was used to compare the pretreatment and posttreatment clinical data. The Frankel grade before the surgery and at the last follow-up were compared using the Wilcoxon signed rank test. The results are reported descriptively or as mean \pm standard deviation. A $P$ value of less than .05 was considered statistically significant.

\section{RESULTS}

The mean age was 37.8 years (range, 2-65 years). The average duration of symptoms was 4.4 months (range, 0.5-9 months) before presentation (Table 1). Spinal TB was confirmed in 45 of 49 patients with a biopsy specimen. The mean number of vertebral involvements was 1.7. The mean operation time for the whole group was $320 \pm 21.4$ minutes, with an average blood loss of $962.1 \pm 190 \mathrm{~mL}$. The mean hospital stay for the whole group was 19.4 days. The mean time to fusion was 8.4 months (Table 2). Pain was relieved significantly by 6 weeks postoperation (VAS: 5.6-1.5). The average ESR and CRP returned to normal within 6 months in all patients (Table 2).

Table 2. Summary of treatment outcomes, thoracic to lumbar, mean $\pm S D$.

\begin{tabular}{lcc}
\hline Parameters & Measurements & $\boldsymbol{P}$ Value \\
\hline Operation time, min & $320 \pm 21.4$ & \\
Blood loss, mL & $962.1 \pm 190$ & \\
Hospitalization, d & $19.4 \pm 5$ & \\
Duration of follow-up, mo & $31.5 \pm 9$ & \\
Fusion time, mo & $8.4 \pm 1.4$ & $<.0001$ \\
ESR & $59.2 \pm 17$ & \\
$\quad$ Preoperative & $9.6 \pm 2.9$ & $<.0001$ \\
$\quad$ 6-mo postoperative & $27.3 \pm 6.2$ & $<.0001$ \\
CRP & $2.8 \pm 1$ & \\
$\quad$ Preoperative & & \\
6-mo postoperative & $5.6 \pm 0.9$ & \\
VAS & $1.6 \pm 0.8$ & \\
Preoperative & & \\
Final follow-up &
\end{tabular}

Abbreviations: CRP, C-reactive protein; ESR, erythrocyte sedimentation rate; VAS, visual analog scale. 
Table 3. Neurologic recovery according to Frankel scoring.

\begin{tabular}{|c|c|c|c|c|c|c|c|}
\hline \multirow{2}{*}{$\begin{array}{l}\text { Level of TB Lesion } \\
\text { and Frankel Grade }\end{array}$} & \multirow{2}{*}{$\begin{array}{c}\text { On } \\
\text { Admission }\end{array}$} & \multicolumn{5}{|c|}{$\begin{array}{l}\text { Frankel Grade at } \\
\text { Final Follow-Up }\end{array}$} & \multirow[b]{2}{*}{$P$ Value $^{\mathrm{a}}$} \\
\hline & & $\mathbf{A}$ & B & $\mathbf{C}$ & D & $\mathbf{E}$ & \\
\hline Thoracic & & & & & & & $<.0001$ \\
\hline A & 5 & & & & 1 & 4 & \\
\hline $\mathrm{B}$ & 3 & & & & 2 & 1 & \\
\hline $\mathrm{C}$ & 10 & & & & & 10 & \\
\hline $\mathrm{D}$ & 1 & & & & & 1 & \\
\hline Thoracolumbar & & & & & & & $<.0001$ \\
\hline A & 3 & 1 & & & 1 & 1 & \\
\hline $\mathrm{B}$ & 5 & & & & 2 & 3 & \\
\hline $\mathrm{C}$ & 7 & & & & & 7 & \\
\hline $\mathrm{D}$ & 3 & & & & & 3 & \\
\hline Lumbar/lumbosacral & & & & & & & $<.0001$ \\
\hline A & 0 & & & & & 0 & \\
\hline $\mathrm{B}$ & 1 & & & & & 1 & \\
\hline $\mathrm{C}$ & 7 & & & & & 7 & \\
\hline $\mathrm{D}$ & 4 & & & & & 4 & \\
\hline Total & 49 & & & & & 42 & \\
\hline
\end{tabular}

Abbreviation: TB, tuberculosis.

${ }^{\mathrm{a}}$ Wilcoxon signed rank test, follow-up compared with preoperation.

In the thoracic spine group, 12 patients received a titanium mesh cage filled with cancellous graft, 4 patients had a strut graft with ribs, and 3 patients had expandable cages (Globus Medical Inc, Audubon, PA). In the thoracolumbar spine group, strut grafts in 4 patients, titanium mesh cages with cancellous graft in 11 patients, and expandable cages in 3 patients were used. In the lumbar/ lumbosacral spine group, 8 patients had mesh cage (wrapping cancellous graft), 3 had expandable cages, and 1 patient had a stand-alone L5-S1 cage. Two children below 10 years of age underwent anterior corpectomy and debridement with rib or fibular grafts and posterior instrumented fusion.

The neurological deficit in 42 of 49 patients had excellent or good clinical outcome $(P<.0001)$ (Table 3). Ten of 17 patients improved from Frankel $\mathrm{A}$ and $\mathrm{B}$ to Frankel E (normal activity). Three patients each in the thoracic and thoracolumbar groups improved to Frankel D. A total of 32 patients improved from Frankel C and D to Frankel E. One patient with T11-T12 involvement had no return of neurological function. Plain lateral radiography showed signs of bony fusion, graft consol- idation, remodeling and hypertrophy, and sclerosis of contiguous surface of disc spaces.

Radiological measurements showed 19 patients in the thoracic group had a mean preoperative kyphosis of $29.5^{\circ} \pm 8.8^{\circ}$, which was corrected to $11.1^{\circ} \pm 2.4^{\circ}$ at final follow-up. Eighteen patients in the thoracolumbar segment had a mean kyphosis of $36.1^{\circ} \pm 8.6^{\circ}$, which was corrected to $12.1^{\circ} \pm 2.7^{\circ}$ at final follow-up. The remaining 12 patients in the lumbar group had a mean preoperative kyphosis of $26.0^{\circ} \pm 2.7^{\circ}$, which was corrected to $8.6^{\circ} \pm 1.2^{\circ}$ at final follow-up. No significant loss of deformity correction was noted at the final follow-up (Table $4)$.

\section{Complications}

All patients had good postoperative recovery. Perioperative bleeding complications were reported for 2 patients. There were 3 patients who had superficial infections of a posterior wound that healed with antibiotics and regular dressing. Two patients with deep infections required debridement and irrigation followed by antibiotics and dressing. Two patients had malpositioning of thoracic screws; 1 of these patients had infection and loosening. Both had revision of posterior implants. One patient who had previous surgery for cement disease at D11-D12 had revision with an expandable cage and extension of the pedicle instrumentation. She was found to have a TB lesion on biopsy at the time of cage insertion. The expandable cage displaced after a year and increased her neurological deficit. She underwent revision with removal of the cage, bone graft, and fixation of vertebrae.

One patient had previous posterior-only fusion from L2 to S1-S2 for a TB lesion of L5 with focal kyphosis. She underwent re-exploration, debridement, and reinstrumentation. At L5-S1, she received an expandable cage with bone grafts and revised posterior instrumentation. She had MDR-TB, which was treated appropriately. She recovered completely by the end of 18 months after the

Table 4. Kyphosis correction postsurgery and at final follow-up in respective spinal levels. ${ }^{a}$

\begin{tabular}{|c|c|c|c|c|c|c|c|}
\hline \multirow[b]{2}{*}{ Level of Lesion } & \multirow{2}{*}{$\frac{\text { Preoperative }}{\text { Kyphosis Angle, }^{\circ}}$} & \multicolumn{3}{|c|}{ Postoperative } & \multicolumn{3}{|c|}{ Follow-Up } \\
\hline & & Kyphosis Angle, $^{\circ}$ & Angle Correction, ${ }^{\circ}$ & \% Correction & Kyphosis, Angle, & Angle Lost, ${ }^{\circ}$ & $\%$ Final Correction \\
\hline Thoracic & $29.5 \pm 8.8$ & $8.8 \pm 2.3$ & $20.7 \pm 6.8$ & $69.4 \pm 5.3$ & $11.1 \pm 2.4$ & $2.3 \pm 0.6$ & $61 \pm 7.1$ \\
\hline Thoracolumbar & $36.1 \pm 8.6$ & $9.7 \pm 2.8$ & $19.8 \pm 7.1$ & $72.7 \pm 5.5$ & $12.1 \pm 2.7$ & $2.2 \pm 0.5$ & $66 \pm 7.1$ \\
\hline Lumbar & $26.0 \pm 2.7$ & $6.2 \pm 1.2$ & $19.8 \pm 2.8$ & $75.8 \pm 5.1$ & $8.6 \pm 1.2$ & $2.3 \pm 0.6$ & $67 \pm 4.9$ \\
\hline
\end{tabular}

${ }^{a}$ Comparison of postoperative kyphosis angle with preoperative kyphosis angle in the 3 groups: thoracic, $P<.0001 ;$ thoracolumbar, $P<.0001$; lumbar, $P<.0001$. In contrast, the comparison of the final follow-up kyphosis angle with the postoperative kyphosis angle in the 3 groups revealed no significant difference. 
revision surgery. The 2-year-old child had anterior surgical debridement at T12 followed by posterior pedicle instrumentation. She had developed progressive mild kyphosis with completely healed lesion and fusion at T12-L1 at the age of 6 years. She underwent removal of posterior instrumentation and as of the last follow-up was growing normally.

\section{DISCUSSION}

Eight countries accounted for two thirds of the global burden of tuberculosis, of which India tops the list with $27 \%$ of all cases. ${ }^{24}$ Although the thoracic and thoracolumbar spine is most commonly affected, lumbosacral spine involvement is rare. ${ }^{7,25,26}$ The mainstay of treatment for spinal TB with or without neurological deficit is antituberculosis medication. Many authors have observed that concomitant TB of the lung was present in $20 \%-45 \%$ patients who were treated preoperatively with ATT. ${ }^{27-29}$ A short delay in surgical decompression does not significantly alter the long-term recovery of neurological function in a gradually developing neural deficit. Few patients show signs of improvement while waiting for surgery. ${ }^{30}$ In the present series, none improved their neurological state following the 4 weeks of preoperative ATT (as followed by previous authors as protocol in their series). ${ }^{13-21}$

TB osteomyelitis is caused predominantly by spread via the paravertebral venous plexus, and the lesion usually commences in the anterior-inferior vertebral body with spread under the anterior spinal ligament to adjacent inferior vertebra. ${ }^{31}$ Anterior involvement is mostly due to the spread of the abscess under the ligaments and periosteum. There is a predilection of involvement of upper lumbar and lower thoracic spine. ${ }^{32}$ The general consensus is that a large abscess, severe bone destruction, spinal cord compression with neurological deficits, and/or kyphotic deformity preclude surgical debridement.

Neurological deficits can vary according the level and extent of the disease. A single-stage anterior and posterior surgery is feasible and safe even in a less advanced surgical center such as ours. Spinal decompression, debridement, and bone grafting (direct or indirect) through an anterolateral approach is practiced at many centers. The anterior instrumentation has been increasingly applied since it was reported that titanium alloy implants were safe for spinal $\mathrm{TB}^{33}$ This should be followed up with a posterior decompression and instrumented fusion to stabilize the spinal segment and achieve a bony fusion. Such fusion of the vertebrae is thought to be the most reliable evidence of healing of spinal TB.

In many of the published studies, the ATT regimen was followed for 12 months (Table 5), but few had persisted with 18-24 months. ${ }^{13,18,19,38}$ Although the World Health Organization does not give much attention to spinal TB, the MRC working committee suggests good results with 18-month regimens containing rifampicin, whereas the results of the 9-month regimens of isoniazid plus PZA (pyrizinamide) or ethambutol were clearly inferior. ${ }^{39}$ In this series, we continued the ATT for 18 months until there was full physical activity with clinically and radiographically quiescent disease and functional improvement. In the Indian subcontinent many patients are noncompliant and have a higher recurrence rate. Therefore, to be safe we have extended the time period of ATT to at least 18 months.

\section{Thoracic TB}

In the thoracic spinal $\mathrm{TB}$, the combined A-P procedure can be performed in 1 or 2 stages. Posterior instrumentation reduces the stress on grafts placed anteriorly, thus supporting the sagittal deformity correction. ${ }^{4,36}$ Jain et $\mathrm{al}^{36}$ suggested that the anterior surgery can significantly improve the kyphosis angle and VAS score in patients with thoracic vertebral TB. A critical preoperative evaluation should indicate the potential for risk of loss of the kyphosis angle (due to multisegmental disease), which will enable a decision with regard to a combined A-P surgery. ${ }^{13}$ The appropriate surgical procedure should be determined according to the position and extent of the lesion, the patient's general condition, and the types of complications. ${ }^{40}$ Rajasekaran et $\mathrm{al}^{41}$ suggested that a combined approach should be reserved for severe destructive lesions and junctional unstable lesions. It is well known that anterior surgery is more anatomically complex than posterior surgery, and it takes a longer surgical time for a combined procedure.

More than 2 decades ago, Moon et $\mathrm{al}^{42}$ concluded that a combined procedure provides early fusion, prevents progression of kyphosis, and corrects the kyphosis. Initially they performed the surgery in 2 stages, but later combined the A-P procedure in a single stage. Since then, a single-stage combined procedure has been practiced at many centers. The 
Table 5. Previously published results with remarks on thoracolumbar tuberculosis with neurological deficit.

\begin{tabular}{|c|c|c|c|c|c|c|}
\hline $\begin{array}{l}\text { Serial } \\
\text { No. }\end{array}$ & $\begin{array}{c}\text { Lead } \\
\text { Author, } y\end{array}$ & $\begin{array}{l}\text { Neural } \\
\text { Deficit }\end{array}$ & Surgery & $\begin{array}{c}\text { ATT } \\
\text { Duration }\end{array}$ & Outcome & Remark \\
\hline 1 & Laheri $(2001)^{34}$ & $23 / 28$ & $\begin{array}{l}\mathrm{P}+\mathrm{A}, \text { posterior and } \\
\quad \text { anterior }\end{array}$ & $9 \mathrm{mo}$ & $21 / 23(91.3 \%)$ recovery & $\begin{array}{l}\text { Combined posterior } \\
\text { decompression, fixation \& } \\
\text { anterior ICBG, good outcome }\end{array}$ \\
\hline 2 & Benli $(2003)^{35}$ & $25 / 63$ & Anterior only & $12 \mathrm{mo}$ & $80 \%$ full, $16 \%$ partial & Anterior only safe \& efficacious \\
\hline 3 & $\operatorname{Jin}(2003)^{17}$ & $15 / 23$ & Anterior only & $12 \mathrm{mo}$ & $14 / 15(93 \%)$ neuro recovery & $\begin{array}{l}\text { Spinal stability maintenance } \& \\
\text { ATT are prime strategy }\end{array}$ \\
\hline 4 & Zhao $(2007)^{18}$ & $25 / 37$ & $\begin{array}{l}\mathrm{A}+\mathrm{P}, \text { anterior and } \\
\text { posterior }\end{array}$ & $18 \mathrm{mo}$ & $2 / 25$ recovery $(92 \%)$ & $\begin{array}{l}\text { Radical debridement \& ATT key } \\
\text { in healing }\end{array}$ \\
\hline 5 & Jain $(2008)^{36}$ & $27 / 38$ & $\begin{array}{l}\mathrm{P}+\mathrm{A} \text {, posterior } \\
\quad \text { followed by anterior }\end{array}$ & $12 \mathrm{mo}$ & $88 \%(34 / 27)$ recovered & $\begin{array}{l}\text { Single stage posterior fixation and } \\
\text { anterolateral decompression has } \\
\text { good outcome }\end{array}$ \\
\hline 6 & Ma $(2012)^{37}$ & $14 / 78$ & $\begin{array}{l}\mathrm{A}+\mathrm{P}, \text { anterior and } \\
\text { posterior }\end{array}$ & $12 \mathrm{mo}$ & $94 \%$ full recovery & $\begin{array}{l}\text { Recurrences due to inadequate } \\
\text { chemotherapy }\end{array}$ \\
\hline 7 & Wang $(2012)^{14}$ & $13 / 37$ & $\begin{array}{l}\mathrm{P}+\mathrm{A} \text {, posterior } \\
\quad \text { followed by anterior }\end{array}$ & $12 \mathrm{mo}$ & $\begin{array}{l}100 \%(13 / 13) \text { recovery, } \\
\text { effective kyphosis correction }\end{array}$ & $\begin{array}{l}\text { Single-stage posterior fixation and } \\
\text { anterior debridement with } \\
\text { fusion \& ATT has good } \\
\text { outcome }\end{array}$ \\
\hline 8 & $\mathrm{Pu}(2012)^{19}$ & $\begin{array}{l}10 / 22(\mathrm{~A}) \\
13 / 25(\mathrm{P})\end{array}$ & Anterior vs posterior & $18 \mathrm{mo}$ & $\begin{array}{l}\text { A: } 100 \% \text { full recovery; P: } 11 / 13 \\
\text { full recovery }\end{array}$ & $\begin{array}{l}\text { Anterior approach for lesion in } \\
\text { anterior and middle column }\end{array}$ \\
\hline 9 & Wang $(2014)^{16}$ & $\begin{array}{l}44 / 55 \text { (Male) } \\
45 / 60 \text { (Female) }\end{array}$ & $\begin{array}{l}\text { Gr A: A + P vs } \\
\text { Gr B: P + A }\end{array}$ & $12 \mathrm{mo}$ & $\begin{array}{l}\text { Gr A: } 34 / 44 \text { full neuro recovery; } \\
\text { Gr B: } 36 / 45 \text { full neuro recovery }\end{array}$ & $\begin{array}{l}\text { Single posterior debridement/bone } \\
\text { grafting/fixation may be the } \\
\text { best when no psoas abscess }\end{array}$ \\
\hline 10 & Cheng $(2015)^{38}$ & $16 / 43$ & $\begin{array}{l}\mathrm{A}+\mathrm{P}, \text { Anterior and } \\
\text { posterior }\end{array}$ & $>12 \mathrm{mo}$ & $93.7 \%$ recovery & $\begin{array}{l}\text { Combined surgery, pre-op \& post- } \\
\text { op ATT has good outcome }\end{array}$ \\
\hline 11 & Cui $(2016)^{20}$ & $23 / 81$ & $\begin{array}{l}\text { A }-11 \\
P-12\end{array}$ & $12 \mathrm{mo}$ & $\begin{array}{l}\text { A: } 10 / 11 \text { full recovery } \\
\text { P: } 10 / 12 \text { full recovery }\end{array}$ & $\begin{array}{l}\text { Anterior only or posterior only } \\
\text { can achieve good results }\end{array}$ \\
\hline 12 & Zhou $(2018)^{21}$ & $\begin{array}{l}30 / 34 \text { (P only) } \\
28 / 30 \\
(\mathrm{~A}+\mathrm{P})\end{array}$ & $\begin{array}{l}\mathrm{P} \text { vs } \mathrm{A}+\mathrm{P} \\
\text { Posterior only vs } \\
\text { anterior and } \\
\text { posterior }\end{array}$ & $12 \mathrm{mo}$ & $\begin{array}{l}\text { P: } 27 / 30 \text { full recovery } \\
\text { A }+ \text { P: } 25 / 28 \text { full recovery }\end{array}$ & $\begin{array}{l}\text { Single posterior approach is a } \\
\text { favorable method }\end{array}$ \\
\hline 13 & Liu $(2020)^{13}$ & $\begin{array}{l}28 / 35(\mathrm{~A}) \\
31 / 43(\mathrm{P})\end{array}$ & $\begin{array}{l}\text { A: } 35 \\
\text { P: } 43\end{array}$ & $18 \mathrm{mo}$ & $100 \%$ & $\begin{array}{l}\text { Single anterior or single posterior } \\
\text { are both efficacious }\end{array}$ \\
\hline
\end{tabular}

Abbreviations: A, anterior; ATT, antituberculosis therapy; Gr, grade; ICBG, iliac crest bone graft; P, posterior.

factors leading to excellent or good outcomes are manifold but are mostly due to an experienced surgical team, which reduces the surgical time as well as complications associated with the combined procedure. Wang et $\mathrm{al}^{14}$ suggested a single-stage A$\mathrm{P}$ procedure is safe and effective for multilevel tuberculous spondylitis of the upper thoracic region, which can achieve goals of complete spinal cord decompression and good deformity correction. In this series, it was observed that anterior debridement allows surgeons to remove the abscess completely, debride the abscess cavity, correct the deformity, and achieve direct neural decompression with rigid anterior reconstruction. Postoperatively, $69 \%$ kyphotic deformity correction was achieved. At final follow-up, the correction was satisfactorily preserved with mean loss of correction at $2.3^{\circ}$. This is quite similar to the correction achieved by Laheri et $\mathrm{al}^{34}(62.5 \%)$ in their series of 38 patients who underwent single-stage combined A-P procedure. Literature suggests the kyphotic correction was achieved in $45 \%-78.5 \%$ of patients in the thoracic spine. ${ }^{14,34,36,42,43}$ The tuberculous granulation tissue around the spinal cord renders it vulnerable to damage if the surgeons are overzealous in correcting the kyphosis. This puts the cord in more tension and may cause permanent damage to the patient. We believe that the significant improvement in the neurological outcome in $84 \%$ of the patients in this series was due to meticulous reconstruction of the spinal segment along with compliant anti-TB medication (Figure 1a-1h).

\section{Thoracolumbar TB}

The thoracolumbar area is a transition from a relatively fixed thoracic vertebra and a relatively mobile lumbar spine; therefore, the risk of back pain and paraplegia is greater once the disease affects the cauda equine and nerve roots. It is believed that based on the strictly mastered indications and better surgical time, a combined A-P surgery can obtain satisfactory clinical effects in thoracolumbar TB. ${ }^{38}$ In clinical practice, the surgical approach should be selected according to the characteristics of the lesion, the technical proficiency of the surgeon, and the imaging findings. ${ }^{44,45}$ Surgery by combined A-P procedure allows for extensive abscess debride- 

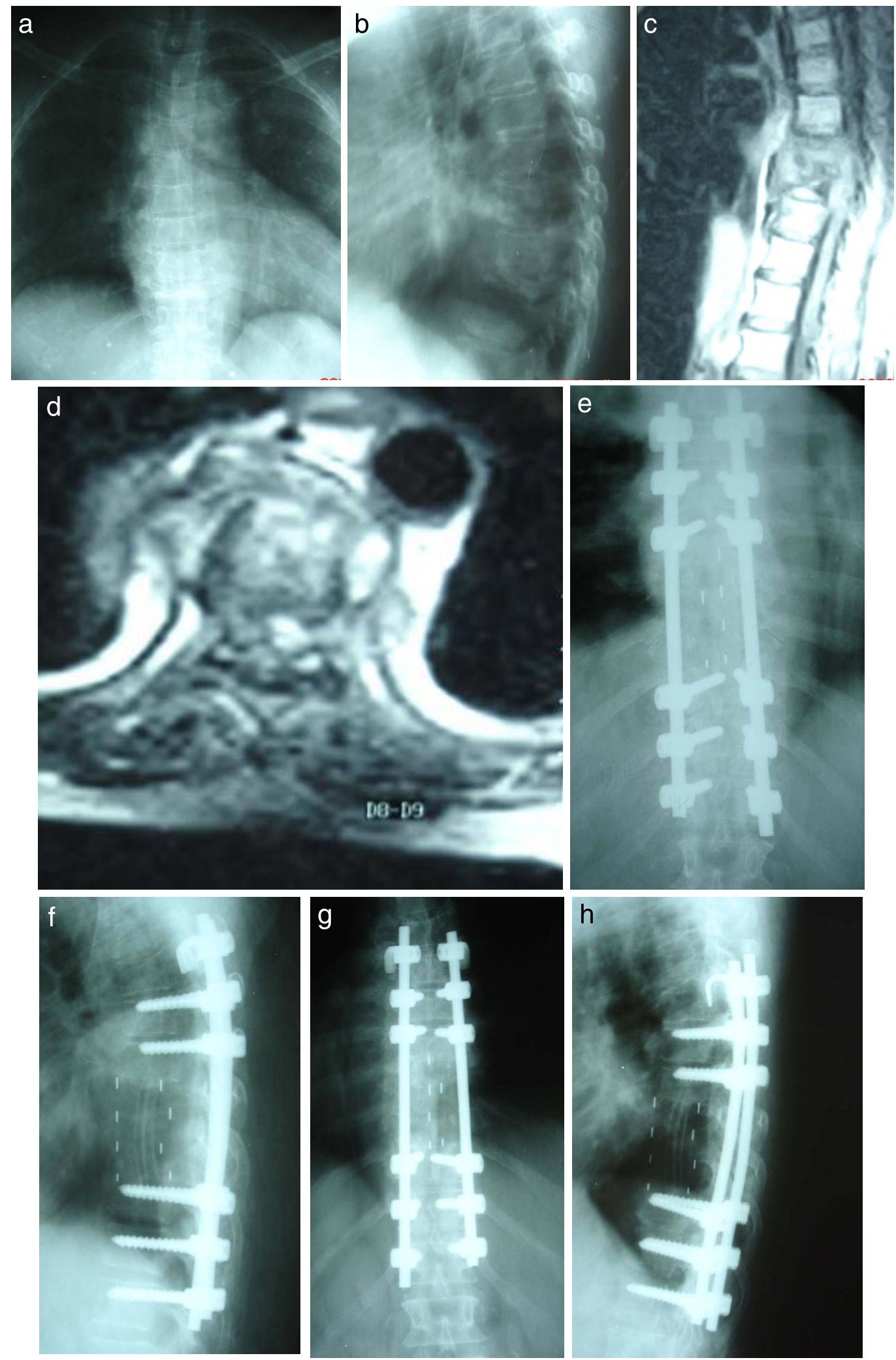

Figure 1. A 58-year-old woman with thoracic (D8-D9) tuberculosis (TB) and paraplegia of 4 months' duration. (a) X-ray antero-posterior view showing D8-D9 collapse. (b) X-ray lateral view showing D8-D9 collapse. (c) MRI (T2 sagittal view) showing the extent of the lesion with compression of the spinal cord. (d) MRI (T2 axial view) showing the extent of the lesion with abscess at D8-D9. (e) 2 weeks' postoperative x-ray antero-posterior view showing corpectomy and cage fusion with rib grafts in situ. (f) 2 weeks postoperative x-ray lateral view showing corpectomy and cage fusion with rib grafts in situ. (g) 3 years' postoperative x-ray antero-posterior view showing healed TB lesion with bony fusion. (h) 3 years' postoperative $x$-ray lateral view showing healed TB lesion with bony fusion. 
ment and spinal canal decompression, which is beneficial for reducing the spread of TB. ${ }^{15}$ In this series, $77 \%$ patients had normal function by the end of 8 months. This study encountered the disadvantages of surgery as others did: increased operative time, blood loss, and hospital stay. ${ }^{15,41,46}$

Wang et $a 1^{16}$ evaluated 28 patients with thoracolumbar TB who underwent combined A-P procedure. They reported $90.4 \%$ correction of the kyphosis angle with loss of $1.2^{\circ}$ at final follow-up. In this series, we achieved $72 \%$ kyphotic correction and loss of $2.3^{\circ}$ at final follow-up. It was observed that the patients with the expandable cage had about $1.2^{\circ}$ loss of correction at final follow-up. We support the view of Tosun et $\mathrm{al}^{47}$ who observed that loss of sagittal alignment is better prevented with the expandable cages. But overall return of neurological deficit was not influenced by the loss of kyphosis correction.

The 2-year-old child who underwent anterior rib graft at T12-L1 along with posterior pedicle fixation from T10-L2 had healed well. During her growth spurt period at around 6 years of age, she developed a progressive kyphosis at the thoracolumbar segment even though she had solid fusion. Fountain et $\mathrm{al}^{48}$ described the phenomenon of progressive kyphosis in children with spinal tuberculosis after solid anterior fusion. In one third of the children they found posterior-element overgrowth. To prevent further kyphosis, the posterior implants were removed. Currently, the girl is 12 years old with a normally developed spine.

\section{Lumbar/Lumbosacral TB}

The lumbar spine affection leading to neural deficit is usually a very late presentation. A natural lumbar lordosis retards the tendency of anterior disease to cause a kyphosis. ${ }^{25}$ But a significant or progressive neurological deficit represents a large destructive lesion, which is an absolute indication for early surgery. For upper lumbar and midlumbar spine, a few authors have advocated for the anterior focal cleaning and strut graft combined with posterior fixation of the disease segment. ${ }^{16,49}$ Our experience of patients with lumbar disease supports the view because it allows for good postoperative rehabilitation of patients. Hirakawa et $\mathrm{al}^{50}$ reported that the lesion can be reached directly and decompressing the spinal cord effectively. Reconstituting the height of the vertebrae will prevent local shear and axial stresses via bone graft fusion or cage fusion. $^{51}$ A combined A-P procedure is further indicated in patients with severe lower lumbar kyphosis that requires lordosis correction and restoration or in those whom initial anterior instrumentation failed. ${ }^{37}$ Posterior pedicle fixation can overcome the shortcomings of anterior instrumentation. During surgery, if a 3-column structure of involved vertebrae was destroyed, then corpectomy followed by debridement of the cranial and caudal vertebral end plates and insert instrumentation was carried out. Ying et $\mathrm{al}^{49}$ suggested that an individualized operation was indispensable on the basis of the range of vertebral lesions and the surgical approach.

The rate of kyphosis correction was improved by anterior instrumentation $(79.7 \% \pm 20.1 \%)$ and was effective in maintaining it, with an average loss of $1.1^{\circ} \pm 1.7^{\circ} .{ }^{35} \mathrm{~A}$ mean of $18^{\circ}$ of kyphosis correction was achieved in adult patients at final follow-up after anterior instrumented surgery. ${ }^{17}$ In our series, a mean of $19.8^{\circ}$ of kyphosis correction was achieved with a loss of $2.2^{\circ}$ at final follow-up. It was observed that use of titanium mesh or expandable cages offers better sagittal balance, minimal loss of kyphosis correction, and minimal complications. Fusion rates are as good as iliac bone or rib grafts. The cages offer immediate stability to the anterior column, and posterior pedicle instrumentation allows for large compressive forces to be transferred on the lumbar spine. ${ }^{52}$ It obviates the need for harvesting bone grafts from the iliac region. In our experience, expandable cages offered better mechanical stability and loss of correction was minimal at final followup (Figure $2 \mathrm{a}-2 \mathrm{~g}$ ). It has been reported that mesh cage subsidence occurs with varying severity due to weakened vertebral bodies. But this subsidence did not affect the functional outcome following reconstruction in spinal TB. ${ }^{53}$ We support this view despite loss of kyphosis correction; pain in the lumbosacral area and radicular pain in the lower extremities disappeared, and all patients had 100\% return of normal neurological function. Similar outcomes were reported for 18 patients who had complete pain relief and complete neurological improvement. ${ }^{54}$ There was no incidence of neurologic exacerbation after surgery and there was no recurrence of disease in any patient.

\section{Strength of the Study}

This is a prospective study of a complex disease that causes variable destruction of spinal elements. 

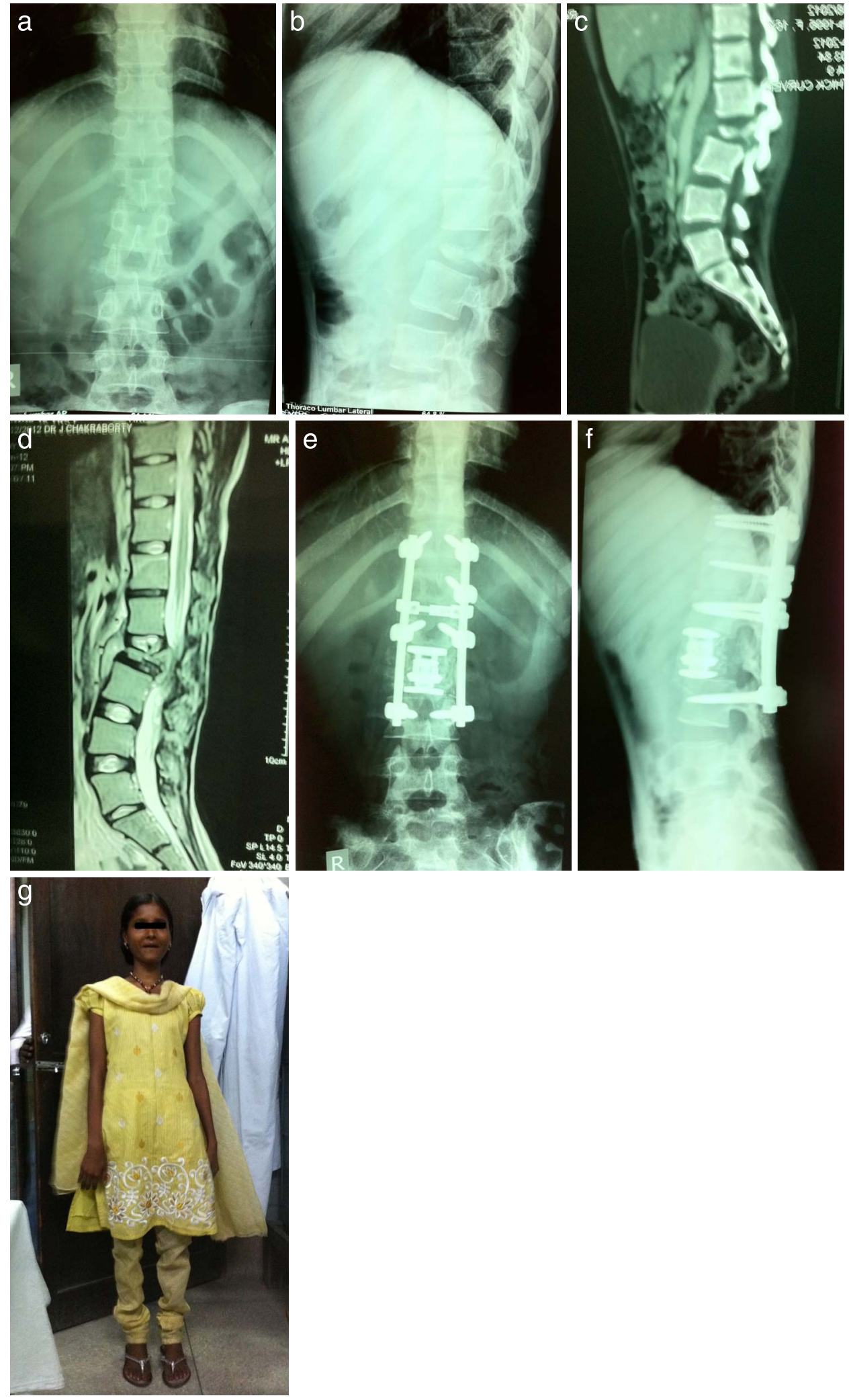

Figure 2. A 15-year-old girl presented with $\mathrm{L} 2$ vertebral collapse due to tuberculosis with complete paraplegia. (a) X-ray antero-posterior view showing collapse at $\mathrm{L} 2$ segment. (b) X-ray antero-posterior view showing collapse of L2 vertebrae with kyphosis. (c) Computed tomography scan sagittal view showing complete destruction of L2 with spinal cord compromise. (d) MRI (T2 sagittal view) showing the extent of the lesion with compression of the spinal cord. (e) 3 years' postoperative x-ray antero-posterior view showing corpectomy and expandable cage with autologous bone graft fusion (between L1 lower end plate and L3 upper end plate). (f) 3 years' postoperative x-ray lateral view showing bone fusion between L1-L3. (g) Clinical photograph at 3-year follow-up with complete recovery. 
The results of thoracic, thoracolumbar, and lumbar/ lumbosacral were separately evaluated, which had not been summarily reported previously. This is an outcome analysis of a specific procedure (ie, singlestage combined A-P surgery with instrumentation over a long period of follow-up).

\section{Limitations of the Study}

The group for each spinal region includes a relatively small number of patients. Finding a large number of patients with a neurological deficit following a destructive tuberculous lesion that requires a combined procedure is a challenge. This study does not compare the other procedures practiced for the disease (eg, anterior- or posterior-only procedures). A prospective comparative study with a long follow-up is recommended.

\section{CONCLUSIONS}

Single-stage anterior corpectomy with autogenous rib grafts or cage insertion and posterior instrumentation are safe and effective methods in the surgical management of spinal TB with neurological deficit. Combined single-stage surgery helps to correct and maintain the deformity, abscess clearance, spinal cord decompression, and pain relief as well as return to normal motor function in the treatment of tuberculous spondylitis. This is efficacious for all spinal vertebral levels and the surgical decision depends on the patient's health status, amount of vertebral destruction, and kyphotic deformity.

\section{REFERENCES}

1. Pott P. Palsy of the Lower Limbs, Chirurgical Works of Percival Pott. Esq., Vol. III, p. 482. The Classics of Medicine Library. 1985.

2. Dobson J. Percivall Pott. Ann $R$ Coll Surg Engl. 1972;50(1):54-65.

3. Merritt ES. Potts disease. Cal State Med J. 1903;1(3):9293.

4. Turgut M. Spinal tuberculosis (Pott's disease): its clinical presentation, surgical management, and outcome. A survey study on 694 patients. Neurosurg Rev. 2001;24:8-13.

5. Rasouli MR, Mirkoohi M, Vaccaro AR, Yarandi KK, Rahimi-Movaghar V. Spinal tuberculosis: diagnosis and management. Asian Spine J. 2012;6(4):294-308.

6. Sai Kiran NA, Vaishya S, Kale SS, Sharma BS, Mahapatra AK. Surgical results in patients with tuberculosis of the spine and severe lower-extremity motor deficits: a retrospective study of 48 patients. $J$ Neurosurg Spine. 2007;6:320-326.

7. Zaveri GR, Mehta SS. Surgical treatment of lumbar tuberculous spondylodiscitis by transforaminal lumbar interbody fusion (TLIF) and posterior instrumentation. $J$ Spinal Disord Tech. 2009;22:257-262.

8. Machino M, Yukawa $\mathrm{Y}$, Ito $\mathrm{K}$, et al. A new thoracic reconstruction technique "transforaminal thoracic interbody fusion": a preliminary report of clinical outcomes. Spine (Phila Pa 1976). 2010;35:E1000-E1005.

9. Zhang HQ, Lin MZ, Li JS, et al. One-stage posterior debridement, transforaminal lumbar interbody fusion and instrumentation in treatment of lumbar spinal tuberculosis: a retrospective case series. Arch Orthop Trauma Surg. 2013;133:333-341.

10. Shah Alam M, Phan K, Karim R, et al. Surgery for spinal tuberculosis: a multi-center experience of 582 cases. $J$ Spine Surg. 2015;1(1):65-71.

11. A controlled trial of ambulant outpatient treatment and in-patient rest in bed in the management of tuberculosis of the spine in young Korean patients on standard chemotherapy a study in Masan, Korea. First report of the Medical Research Council working party on tuberculosis of the spine. J Bone Joint Surg Br. 1973;55:678-697.

12. Rajasekaran S, Shanmugasundaram TK. Prediction of the angle of Gibbus deformity in tuberculosis of the spine. $J$ Bone Joint Surg Am. 1987;69:503-509.

13. Liu H, Luo J, Wang X, Dong X, Hao D. Efficacy of surgery via the single anterior and single posterior approaches for treatment of thoracic spinal tuberculosis. J Int Med Res. 2020;48(1):1-11.

14. Wang XB, Li J, Lu GH, Wang B, Lu C, Kang YJ. Single-stage posterior instrumentation and anterior debridement for active tuberculosis of the thoracic and lumbar spine with kyphotic deformity. Int Orthop. 2012;36:373-380.

15. Tang Y, Wu W, Yang S, et al. Surgical treatment of thoracolumbar spinal tuberculosis - a multicentre, retrospective, case-control study. J Orthop Surg Res. 2019;14(233):1-7.

16. Wang X, Pang X, Wu P, Luo C, Shen X. One-stage anterior debridement, bone grafting and posterior instrumentation vs. single posterior debridement, bone grafting, and instrumentation for the treatment of thoracic and lumbar spinal tuberculosis. Eur Spine J. 2014;23(4):830-837.

17. Jin D, Dongbin Q, Chen J, et al. One-stage anterior interbody autografting and instrumentation in primary surgical management of thoracolumbar spinal tuberculosis. Eur Spine J. 2003;13:114-121.

18. Zhao J, Lian XF, Hou TS, et al. Anterior debridement and bone grafting of spinal tuberculosis with one-stage instrumentation anteriorly or posteriorly. Int Orthop. 2007;31:859-863.

19. Pu X, Zhou Q, He Q, Dai F, Xu J, Zhang Z, Branko K. A posterior versus anterior surgical approach in combination with debridement, interbody autografting and instrumentation for thoracic and lumbar tuberculosis. Int Orthop. 2012;36:307313.

20. Cui X, Li L, Ma Y. Anterior and posterior instrumentation with different debridement and grafting procedures for multi-level contiguous thoracic spinal tuberculosis. Orthop Surg. 2016;8:454-461.

21. Zhou Y, Li W, Liu J, et al. Comparison of single posterior debridement, bone grafting and instrumentation with single-stage anterior debridement, bone grafting and posterior instrumentation in the treatment of thoracic and thoracolumbar 
spinal tuberculosis. BMC Surg. 2018;18(1):71. doi:10.1186/ s12893-018-0405-4

22. Jain AK. Tuberculosis of the spine: a fresh look at an old disease. J Bone Joint Surg Br. 2010;92:905-913.

23. Hodgson AR, Stock FE, Fang HS, Ong GB. Anterior spinal fusion. The operative approach and pathological findings in 412 patients with Pott's disease of the spine. Br J Surg. 1960;48:172-178.

24. Garg RK, Malhotra HS, Kumar N. Spinal tuberculosis: still a great mimic. Neurol India. 2019;67:1402-1404.

25. Bhojraj S, Nene A. Lumbar and lumbosacral tuberculous spondylodiscitis in adults: redefining the indications for surgery. J Bone Joint Surg Br. 2002;84:530-534.

26. Song JF, Jing ZZ, Chen B, Ai ZS, Hu W. One-stage anterolateral surgical treatment for lumbosacral segment tuberculosis. Int Orthop. 2012;36:339-344.

27. Weng CY, Chi CY, Shih PJ, et al. Spinal tuberculosis in non-HIV-infected patients: 10 year experience of a medical center in central Taiwan. $J$ Microbiol Immunol Infect. 2010;43(6):464-469.

28. Jain AK. Treatment of tuberculosis of the spine with neurologic complications in symposium on osteo-articular tuberculosis. Clin Orthop Rel Res. 2002;398:75-84.

29. Schlesinger N, Lardizabal A, Rao J, Rao J, McDonald R. Tuberculosis of the spine: experience in an inner city hospital. J Clin Rheumatol. 2005;11:17-20.

30. Jain AK, Kumar J. Tuberculosis of spine: neurological deficit. Eur Spine J. 2013;22(suppl 4):S624-S633.

31. Pandita A, Madhuripan N, Pandita S, Hurtado RM. Challenges and controversies in the treatment of spinal tuberculosis. J Clin Tuberc Other Mycobact Dis. 2020;19:100151, p1-7.

32. Moorthy S, Prabhu NK. Spectrum of MR imaging findings in spinal tuberculosis. AJR Am $J$ Roentgenol. 2002;179:979-983.

33. Oga M, Arizono T, Takasita M, Sugioka Y. Evaluation of the risk of instrumentation as a foreign body in the spinal tuberculosis: clinical and biologic study. Spine (Phila Pa 1976). 1993;18:1890-1894.

34. Laheri VJ, Badhe NP, Dewnany GT. Single stage decompression, anterior interbody fusion and posterior instrumentation for tuberculous kyphosis of the dorso-lumbar spine. Spinal Cord. 2001;39(8):429-436.

35. Benli IT, Acaroğlu E, Akalin S, et al. Anterior radical debridement and anterior instrumentation in tuberculosis spondylitis. Eur Spine J. 2003;12:224-234.

36. Jain AK, Dhammi IK, Prashad B, Sinha S, Mishra P. Simultaneous anterior decompression and posterior instrumentation of the tuberculous spine using an anterolateral extrapleural approach. J Bone Joint Surg Br. 2008;90:1477-1481.

37. Ma YZ, Cui X, Li HW, et al. Outcomes of anterior and posterior instrumentation under different surgical procedures for treating thoracic and lumbar spinal tuberculosis in adults. Int Orthop. 2012;36(2):299-305.

38. Cheng Z, Wang J, Zheng Q, Wu Y, Guo X. Anterolateral radical debridement and interbody bone grafting combined with transpedicle fixation in the treatment of thoracolumbar spinal tuberculosis. Medicine (Baltimore). 2015;94(14): e721. doi:10.1097/MD.0000000000000721

39. MRC Working Party on Tuberculosis of the Spine. Fiveyear assessment of controlled trials of short-course chemotherapy regimens of 6,9 , or 18 months' duration for spinal tuberculosis in patients ambulatory from the start or undergoing radical surgery. Fourteenth report of the Medical Research Council working party on tuberculosis of the spine. Int Orthop. 1999;23:73-81.

40. Zhang HQ, Guo CF, Xiao XG, Long WR, Deng ZS, Chen J. One-stage surgical management for multilevel tuberculous spondylitis of the upper thoracic region by anterior decompression, strut autografting, posterior instrumentation, and fusion. J Spinal Disord Tech. 2007;20:263-267.

41. Rajasekaran S, Soundararajan DCR, Shetty AP, Kanna RM. Spinal tuberculosis: current concepts. Global Spine J. 2018;8(suppl 4):S96-S108.

42. Moon MS, Woo YK, Lee KS, Ha KY, Kim SS, Sun SH. Posterior instrumentation and anterior interbody fusion for tuberculous kyphosis of dorsal and lumbar spine. Spine (Phila Pa 1976). 1995;17:1910-1916.

43. Louw JA. Spinal tuberculosis with neurological deficit. Treatment with anterior vascularized rib grafts, posterior osteotomies and fusion. J Bone Joint Surg Br. 1990;2:686-693.

44. Li M, Du J, Meng H, Wang Z, Luo Z. One-stage surgical management for thoracic tuberculosis by anterior debridement, decompression and autogenous rib grafts, and instrumentation. Spine J. 2011;11:726-733.

45. Wang Z, Wu Q, Geng G. Anterior debridement and bone grafting with posterior single-segment internal fixation for the treatment of monosegmental spinal tuberculosis. Injury. 2013;44(2):253-257.

46. Memtsoudis SG, Vougioukas VI, Ma Y, Gaber-Baylis LK, Girardi FP. Perioperative morbidity and mortality after anterior, posterior, and anterior/posterior spine fusion surgery. Spine (Phila Pa 1976). 2011;36(22):1867-1877.

47. Tosun B, Erdemir C, Yonga O, Selek O. Surgical treatment of thoracolumbar tuberculosis: a retrospective analysis of autogenous grafting versus expandable cages. Eur Spine J. 2014;23(11):2299-2306.

48. Fountain SS, Hsu LC, Yau AC, Hodgson AR. Progressive kyphosis following solid anterior spine fusion in children with tuberculosis of the spine. A long-term study. $J$ Bone Joint Surg Am. 1975;57(8):1104-1107.

49. Ying XZ, Shi SY, Zheng Q, et al. Treatment of lumbar tuberculosis by mini-open anterior approach focal cleaning combined with posterior internal fixation. Med Sci Monit. 2017;23:4158-4165.

50. Hirakawa A, Miyamoto K, Masuda T, et al. Outcome of 2-stage (posterior and anterior) surgical treatment using spinal instrumentation for tuberculous spondylitis. J Spinal Disord Tech. 2010;23:133-138.

51. Li JH, Zhang ZH, Shi T, et al. Surgical treatment of lumbosacral tuberculosis by one-stage debridement and anterior instrumentation with allograft through an extraperitoneal anterior approach. J Ortho Surg Res. 2015;10(62):1-8.

52. Yin XH, Liu ZK, He BR, Hao DJ. Single posterior surgical management for lumbosacral tuberculosis: titanium mesh cage versus iliac bone graft - a retrospective case control study. Medicine (Baltimore). 2017; 96(51):e9449. doi:10.1097/ MD.0000000000009449

53. Rathod TN, Jogani AB, Marathe N, Masilamani K, Shende CV, Kamble P. Does mesh cage subsidence have any effect on functional outcome in spinal tuberculosis? Asian $J$ Neurosurg. 2019;14(4):1168-1174.

54. Li HJ, Zhang WB, Mo TT, Fang CY. Surgical treatment of lumbosacral tuberculosis by anterior debridement, bone 
graft, and posterior pedicle screw-rod internal fixation. China $J$ Orthop Traumatol (Zhongguo gu shang). 2014;27:829-832.

Disclosures and COI: The authors received no funding for this study and report no conflicts of interest.

Corresponding Author: Dr Ujjwal K. Debnath, 10/1D Swinhoe St, Kolkata 700019, India.
Phone: 0091 9051588823; Email: debs10uk@gmail. com.

Published 1 June 2021

This manuscript is generously published free of charge by ISASS, the International Society for the Advancement of Spine Surgery. Copyright $\odot 2021$ ISASS. To see more or order reprints or permissions, see http://ijssurgery.com. 